\title{
E-2-hexenal promotes susceptibility to Pseudomonas syringae by activating jasmonic acid pathways in Arabidopsis
}

\section{Alessandra Scala ${ }^{1}$, Rossana Mirabella ${ }^{1}$, Cynthia Mugo ${ }^{2}$, Kenji Matsui ${ }^{2}$, Michel A. Haring ${ }^{1}$ and Robert C. Schuurink ${ }^{1}$ *}

1 Department of Plant Physiology, Swammerdam Institute for Life Sciences, University of Amsterdam, Amsterdam, Netherlands

${ }^{2}$ Department of Biological Chemistry, Faculty of Agriculture, Graduate School of Medicine, Yamaguchi University, Yamaguchi, Japan

\section{Edited by:}

Marcel Dicke, Wageningen University, Netherlands

\section{Reviewed by:}

Choong-Min Ryu, Korea Research Institute of Bioscience and Biotechnology, South Korea Eric Kemen, Max Planck Institute for Plant Breeding Research, Germany Marcel Dicke, Wageningen University, Netherlands

\section{*Correspondence:}

Robert C. Schuurink, Department of Plant Physiology, Swammerdam Institute for Life Sciences, University of Amsterdam, Science Park 904, 1098 XH Amsterdam, Netherlands. e-mail: r.c.schuurink@uva.nl
Green leaf volatiles (GLVs) are C6-molecules - alcohols, aldehydes, and esters - produced by plants upon herbivory or during pathogen infection. Exposure to this blend of volatiles induces defense-related responses in neighboring undamaged plants, thus assigning a role to GLVs in regulating plant defenses. Here we compared Arabidopsis thaliana ecotype Landsberg erecta (Ler) with a hydroperoxide lyase line, $h p / 1$, unable to synthesize GLVs, for susceptibility to Pseudomonas syringae pv. tomato (DC3000). We found that the growth of DC3000 was significantly reduced in the $h p / 1$ mutant. This phenomenon correlated with lower jasmonic acid (JA) levels and higher salicylic acid levels in the hp/1 mutant. Furthermore, upon infection, the JA-responsive genes VSP2 and LEC were only slightly or not induced, respectively, in $h p / 1$. This suggests that the reduced growth of DC3000 in $h p / 1$ plants is due to the constraint of JA-dependent responses. Treatment of $h p / 1$ plants with E-2-hexenal, one of the more reactive GLVs, prior to infection with DC3000, resulted in increased growth of DC3000 in hp/1, thus complementing this mutant. Interestingly, the growth of DC3000 also increased in Ler plants treated with E-2-hexenal. This stronger growth was not dependent on the JA-signaling component MYC2, but on ORA59, an integrator of JA and ethylene signaling pathways, and on the production of coronatine by DC3000. GLVs may have multiple effects on plant-pathogen interactions, in this case reducing resistance to Pseudomonas syringae via JA and ORA59.

Keywords: green leaf volatiles, Pseudomonas syringae, jasmonate, coronatine, hormone crosstalk

\section{INTRODUCTION}

Plants produce green leaf volatiles (GLVs), C6-aldehydes, C6alcohols, and their acetates, through the lipoxygenase (LOX) and hydroperoxide lyase (HPL) pathways. Linoleic and linolenic acid are the substrates for dioxygenation and subsequent cleavage to obtain C6-volatile aldehydes that can be further modified by alcohol dehydrogenases $(\mathrm{ADH})$, an isomerization factor and an acetyltransferase leading to the formation of a bouquet of these volatiles. Intact plants produce only trace amounts of GLVs, whereas these compounds are rapidly emitted in large amounts after wounding, herbivory or pathogen attack (Croft et al., 1993; Turlings et al., 1995; Fall et al., 1999; Shiojiri et al., 2000, 2006a; Heiden et al., 2003).

Green leaf volatiles have been reported to play important roles in different biological processes (Bate and Rothstein, 1998; Arimura et al., 2000; Farag and Paré, 2002; Engelberth et al., 2004; Farag et al., 2005; Ruther and Fürstenau, 2005; Ruther and Kleier, 2005). Herbivory induces very specific sets of GLVs that are perceived by natural predators of the herbivores (Kessler and Baldwin, 2001; Birkett et al., 2003; Gouinguené et al., 2005; Shiojiri et al., 2006a,b). Beside a role in indirect defenses, GLVs also act as airborne signaling molecules regulating plant defense responses. Several studies show that plants themselves upon exposure to GLVs respond by activating wound- and herbivore-induced defenses. Examples of this are found in Zea mays (maize), Citrus jambhiri, Nicotiana attenuata (tobacco), Gossypium hirsutum, Lycopersicon esculentum (tomato), and Arabidopsis thaliana plants where GLV perception induces the transcription of genes known to be involved in defense responses, or in biosynthesis of defense-related secondary metabolites (Bate and Rothstein, 1998; Arimura et al., 2001; Gomi et al., 2003; Weber et al., 2004; Farag et al., 2005; Kishimoto et al., 2005, 2006; Paschold et al., 2006), resulting in the production of defensive compounds (Zeringue, 1992; Bate and Rothstein, 1998; Farag and Paré, 2002; Engelberth et al., 2004; Farag et al., 2005; Ruther and Fürstenau, 2005; Kishimoto et al., 2006; Yan and Wang, 2006). Besides direct defense elicitation, exposure to GLVs, emitted from wounded leaves, has also been shown to prime systemic leaves for augmented defense responses upon future attacks (Engelberth et al., 2004; Kessler et al., 2006; Frost et al., 2007, 2008; Heil and Silva Bueno, 2007). Similarly, the E-2-hexenal released by rice upon planthopper infestation, induces expression of defense-related genes, increasing resistance to bacterial blight (Gomi et al., 2010). In some of these examples the effect of GLVs and jasmonic acid (JA) signaling have been linked (Engelberth et al., 2004; Halitschke et al., 2004; Kishimoto et al., 2006; Allmann et al., 2010; Tong et al., 2012). 
Finally, GLVs possess fungicidal and bactericidal activity (Prost et al., 2005; Shiojiri et al., 2006b). Since GLVs are released after infection with pathogenic fungi and bacteria (Croft et al., 1993; Heiden etal., 2003; Shiojiri etal., 2006b), this suggests that a possible physiological role of these volatiles is to limit pathogen growth. Several observations support this hypothesis. For instance, upon infection with the pathogenic bacteria Pseudomonas syringae, Phaseolus vulgaris (lima bean) leaves release relatively high amounts of the C6-aldehyde E-2-hexenal and the C6-alcohol Z-3-hexenol (Croft et al., 1993). Moreover, pre-treatment with the C6-aldehyde E-2-hexenal as well as genetic manipulation to enhance C6-volatile production, resulted in increased resistance against the necrotrophic fungus Botrytis cinerea in Arabidopsis, most likely as a result of both activation of defense responses and direct inhibition of fungal growth (Kishimoto et al., 2005; Shiojiri et al., 2006b).

Since all this evidence indicates a role for GLVs in regulating plant responses to bacterial pathogens and GLV levels have been shown to increase in plants upon infection with Pseudomonas syringae (Croft et al., 1993; Heiden et al., 2003), we decided to further dissect the role of GLVs in the interaction of plants with this pathogen. Increased GLV levels could directly inhibit the pathogen and/or promote infection through downstream signaling favorable for the pathogen. Pseudomonas syringae pv. tomato DC3000 is a plant pathogen that enters leaves through stomata, multiplies in the apoplast, and produces necrotic lesions with chlorotic halos (Hirano and Upper, 2000). Pseudomonas syringae pv. tomato DC3000 (DC3000) causes bacterial speck on tomato (Cuppels, 1986), but also on A. thaliana (Whalen et al., 1991). DC3000 produces coronatine (COR), a toxin, responsible for chlorotic halos, which mimics the action of JA-isoleucine (JA-Ile), the active form of JA. With this phytotoxin DC3000 exploits the antagonistic interaction between JA and salicylic acid (SA) in order to shut down SA-dependent defenses that plant triggers to fight against Pseudomonas infections (Block et al., 2005; Glazebrook, 2005).

We especially focused on the role of E-2-hexenal during the Arabidopsis-Pseudomonas interaction. Although it is not the most abundant C6-volatile produced by HPL activity, E-2-hexenal is emitted during Pseudomonas ssp. infections in lima bean (Croft et al., 1993) and in tobacco (Heiden etal., 2003), and it has the highest bactericidal activity in vitro among oxylipins (Prost et al., 2005), likely because its $\alpha, \beta$-unsaturated carbonyl moiety that can react with nucleophilic groups (Farmer and Davoine, 2007). Additionally, E-2-hexenal has been shown to induce several responses in Arabidopsis, including induction of defenses, inhibition of root growth and enhancement of resistance against the necrotrophic fungus B. cinerea (Bate and Rothstein, 1998; Kishimoto et al., 2005; Mirabella et al., 2008). In order to determine the role of GLVs in the responses against Pseudomonas, we set out to study Arabidopsis plants with and without a functional HPL (Shiojiri et al., 2012) and did complementation studies with E-2-hexenal. Remarkably we found that the presence of a working copy of HPL increased susceptibility of Arabidopsis to DC3000. Treatment with E-2-hexenal also enhanced the susceptibility to this bacterial pathogen. We found evidence that this is mediated by the transcription factor ORA59, one of the main players in the JA-signaling pathways, and required the production of the bacterial toxin COR.

\section{MATERIALS AND METHODS PLANT LINES}

Arabidopsis thaliana ecotype Columbia-0 (Col-0) and Landsberg erecta (Ler) were used. The hpll mutant is an introgression line between Col-0 and Ler (Shiojiri et al., 2012). The mutant myc2 (jin1-7; Verhage et al., 2011), the transgenic lines RNAi-ORA59 and the 35S:GUS plants (Pré et al., 2008) were all in the Col0 background. Plants were grown in soil in a growth chamber at $21^{\circ} \mathrm{C}, 70 \%$ relative humidity under an 11 -h photoperiod with $100 \mu \mathrm{E} \mathrm{s}^{-1} \mathrm{~m}^{-2}$.

\section{BACTERIAL POPULATION COUNTS}

Bacteria were grown overnight at $28^{\circ} \mathrm{C}$ in liquid King's broth (KB) medium (King et al., 1954) containing rifampicin $(50 \mu \mathrm{g} / \mathrm{ml})$ for the Pseudomonas syringae pv. tomato DC3000 strain, and kanamycin $(100 \mu \mathrm{g} / \mathrm{ml})$ for the cor $^{-}$DC3682 mutant strain, unable to produce COR (Ma etal., 1991). Plants were inoculated with either a low dose $\left(\mathrm{OD}_{600}\right.$ of 0.0007$)$, for bacterial growth assays, or a high dose $\left(\mathrm{OD}_{600}\right.$ of 0.007$)$, for qRT-PCR and hormone quantification, of the bacterial suspension, and bacteria (colony forming units, cfu) were counted as reported in Park et al. (2010).

\section{PLANT HORMONES EXTRACTION AND QUANTIFICATION}

For JA and SA quantification, 12 leaves were harvested, in pools of 4, from 12 different mock-infiltrated $\left(10 \mathrm{mM} \mathrm{MgSO}_{4}\right)$ or bacteriainfiltrated plants in two independent experiments. To extract JA and SA, frozen leaf material (50-150 mg) was ground and homogenized in $0.5 \mathrm{ml} \mathrm{70 \%} \mathrm{methanol,} \mathrm{spiked} \mathrm{with} 200 \mathrm{ng}$ of D6-JA and D6-SA (internal standards for extraction efficiency; CDN Isotopes, Canada ${ }^{1}$ ), with a Precellys 24 automated lyser (Bertin Technologies ${ }^{2}$ ). Samples were homogenized twice by shaking at $6,000 \mathrm{rpm}$ for $40 \mathrm{~s}$ and centrifuged at $10,000 \mathrm{~g}$ for $20 \mathrm{~min}$ at $4^{\circ} \mathrm{C}$. The supernatants of two extraction steps were pooled. Hormones were quantified by liquid chromatography-mass spectrometry (LC-MS) analysis on Varian 320 Triple Quad LC/MS/MS. Ten microliters of each sample were injected onto a C18 Pursuit 5 $(50 \mathrm{~mm} \times 2.0 \mathrm{~mm})$ column (Varian) coupled to a double mass spectrometer in tandem (Varian 320 MS-MS ${ }^{3}$ ). The mobile phase comprised solvent A $(0.05 \%$ formic acid $)$ and solvent B $(0.05 \%$ formic acid in methanol) as follows: $85 \%$ solvent $\mathrm{A}$ for $1 \mathrm{~min}$ $30 \mathrm{~s}$ (flow rate $0.4 \mathrm{ml} / \mathrm{min}$ ), followed by $3 \mathrm{~min}$ in which solvent B increased till $98 \%(0.2 \mathrm{ml} / \mathrm{min})$ which continued for $5 \mathrm{~min} 30 \mathrm{~s}$ with the same flow rate, followed by $2 \mathrm{~min} 30 \mathrm{~s}$ with increased flow rate $(0.4 \mathrm{ml} / \mathrm{min})$, subsequently returning to $85 \%$ solvent $\mathrm{A}$ in $1 \mathrm{~min}$, conditions that were kept till the end of the run, in total $15 \mathrm{~min}$. Compounds were detected in the electrospray ionization negative mode. Molecular ions $[\mathrm{M}-\mathrm{H}]^{-}$at $\mathrm{m} / z 137$ and 209 and 141 and 213 generated from endogenous SA and JA and their internal standards, respectively, were fragmented under $12 \mathrm{~V}$ collision energy. The ratios of ion intensities of their respective daughter ions, $\mathrm{m} / z 93$ and 97 and $\mathrm{m} / z 59$ and 63, were used to quantify endogenous SA and JA, respectively.

\footnotetext{
${ }^{1}$ www.cdnisotopes.com

${ }^{2}$ http://www.bertin.fr

${ }^{3}$ www.home.agilent.com
} 


\section{QUANTITATIVE RT-PCR}

For analysis of transcript levels, total RNA was isolated using Trizol from 10 infiltrated leaves, harvested from 10 different plants, in three independent experiments and treated with TurBo DNAfree $\left(\right.$ Ambion $\left.^{4}\right)$ to remove DNA. cDNA was synthesized from $1 \mu \mathrm{g}$ of total RNA using M-MuLV reverse transcriptase (Fermentas ${ }^{5}$ ), as described by the manufacturer, in a 20 - $\mu$ l reaction that was diluted to $50 \mu \mathrm{l}$ prior to using it for the real-time PCR. This was performed in a $20-\mu \mathrm{l}$ volume containing $2 \mu \mathrm{l}$ of cDNA, $0.4 \mathrm{pmol}$ of specific primer sets for each gene and $10 \mu \mathrm{l}$ of $\mathrm{iTaq}^{\mathrm{TM}}$ SYBR Green Supermix with ROX (Bio-Rad ${ }^{6}$ ). PCR conditions were as follows: $95^{\circ} \mathrm{C}$ for $2 \mathrm{~min} 30 \mathrm{~s}$ (first cycle), $95^{\circ} \mathrm{C}$ for $15 \mathrm{~s}$ and $60^{\circ} \mathrm{C}$ for $30 \mathrm{~s}$ ( $40 \mathrm{cycles})$. To ensure amplification of a single product during the qRT-PCR reactions, a dissociation protocol was performed in which samples were slowly heated from 55 to $95^{\circ} \mathrm{C}$. qRT-PCR was performed using the ABI Prism 7000 real-time PCR detection system (Applied Biosystems) and the data were collected using software (ABI 7000 SDS version 1) provided by the supplier. Transcript levels were normalized to the levels of the SAND gene (At2g28390; Hong et al., 2010) and quantification was performed as described in previous work (Pfaffl, 2001). Primer sequences were as reported in (Anderson and Badruzsaufari, 2004; Czechowski et al., 2005; Park et al., 2010) for PR1, VSP2, LEC, and SAND, respectively.

\section{TRYPAN BLUE AND ANILINE BLUE STAINING}

Trypan blue staining solution was prepared by adding trypan blue to lactophenol (10 ml lactic acid, $10 \mathrm{ml}$ glycerol, $10 \mathrm{ml}$ phenol, and $10 \mathrm{ml}$ distilled water) to a concentration of $2.5 \mathrm{mg} / \mathrm{ml}$. Two volumes of ethanol were added to the trypan blue-lactophenol solution. To visualize plant cell death, mock and DC3000 infected leaf tissues were placed in plates containing staining solution and heated in a microwave at intervals for $1 \mathrm{~min}$. The plates were incubated for $2 \mathrm{~h}$ at room temperature, followed by destaining (three times) in chloral hydrate $(2.5 \mathrm{~g} / \mathrm{ml})$. The leaf tissues were mounted in $70 \%$ glycerol for observations with a microscope. For detection of callose deposition, leaves were incubated for at least $24 \mathrm{~h}$ in $96 \%$ ethanol until all tissues were transparent and stained in $0.01 \%$ aniline blue in $0.15 \mathrm{M} \mathrm{K}_{2} \mathrm{HPO}_{4}(\mathrm{pH}$ 8.5). Leaf tissues were incubated for $1.5-3 \mathrm{~h}$, mounted on slides, and observed under an epifluorescence microscope (AF6000) with UV filter (excitation filter: BP $470 / 40 \mathrm{~nm}$; emission filter: BP 525/50 nm).

\section{CALLOSE QUANTIFICATION}

Callose was quantified from digital photographs as the number of white pixels, covering the whole leaf material, using Photoshop CS7 software. Contrast settings of photographs were adjusted to obtain an optimal separation of the callose signal from the background signal. Callose was selected automatically, using the "Color Range" tool. In cases in which the contrast settings resulted in significant loss of callose signal, due to high autofluorescence of vasculature tissue, callose was selected manually, using the "Magic

\footnotetext{
${ }^{4}$ http://www.ambion.com

${ }^{5}$ http://www.fermentas.com

${ }^{6}$ www.bio-rad.com
}

Wand" tool of Photoshop CS7. Relative callose intensities were quantified as the number of fluorescent callose-corresponding pixels relative to the total number of pixels covering plant material (Luna et al., 2011).

\section{E-2-HEXENAL TREATMENT}

Plants were grown for 3 weeks under the conditions mentioned above before being exposed to volatiles. For the volatile treatment, 10 plants in single pots were placed into airtight glass desiccators (22 1). E-2-hexenal was diluted in methanol, and applied to a sterile cotton swab, placed in an Erlenmeyer flask, between the plants in the desiccators to give a final concentration of $3 \mu \mathrm{M}$. For the control treatment, only methanol was applied. Plants were incubated in the desiccators for $24 \mathrm{~h}$ and subsequently taken out to be placed under the growth conditions described above for $1 \mathrm{~h}$, prior to infiltration with bacteria or mock solution as mentioned above. E-2-hexenal was purchased from SigmaAldrich.

\section{RESULTS}

\section{hpl1 INFLUENCES SUSCEPTIBILITY TO Pseudomonas syringae pv.} tomato (DC3000)

In order to determine whether the ability to synthesize GLVs had an effect on Arabidopsis susceptibility to pathogenic bacteria, we compared Landsberg erecta (HPL, Ler) and an introgression line between Col-0 and Ler that can synthesize only trace amounts of GLVs, hpl1 (Shiojiri etal., 2012), for the susceptibility to Pseudomonas syringae pv. tomato DC3000. To ensure infection throughout the entire leaf, we used the syringe infiltration method since it overcomes stomatal defenses and maximizes the number of responding cells (de Torres Zabala et al., 2009), and bacterial populations were determined 72 hpi (hours post-infection). Figure 1 shows that DC3000 populations were lower in the hpll line. The difference measured in bacterial population between Ler and $h p l 1$ $(\sim 4$.6-fold) was statistically significant $(t$-test $P<0.05)$. This indicates that the hpll line is less susceptible to DC3000 than Ler.

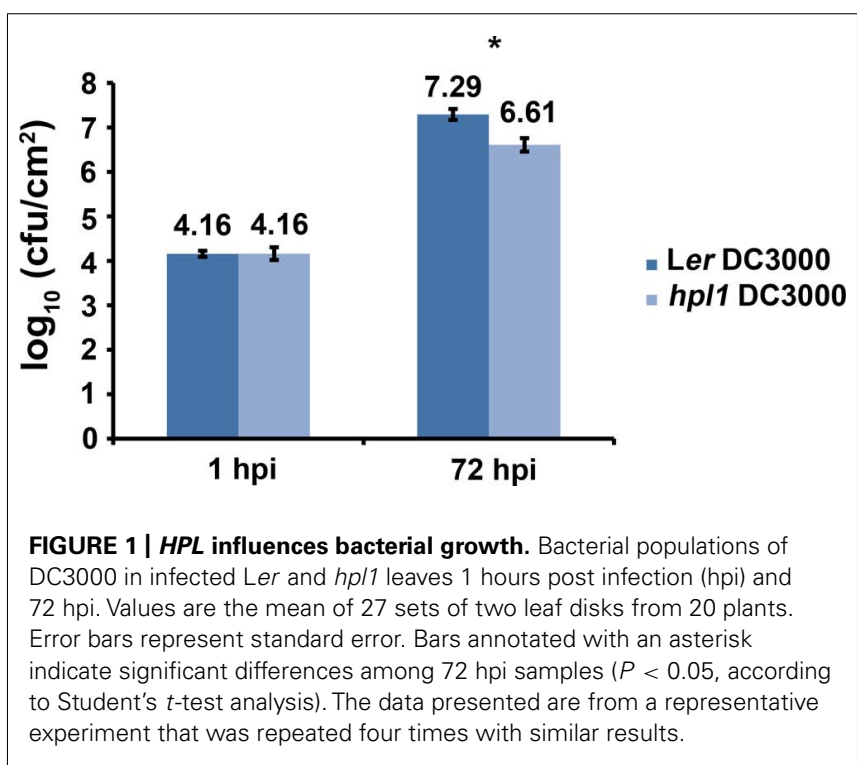




\section{$h p / 1$ INFLUENCES JA AND SA LEVELS DURING THE INFECTION WITH DC3000}

It is well known that the balance between JA and SA is crucial for the interaction that will be established between a pathogen and its host (Spoel and Dong, 2008; Grant and Jones, 2009; Pieterse et al., 2009). We therefore monitored the changes in JA and SA in Ler and the $h p l 1$ plants, prior to the bacterial population measurement, at 2, 24, and 48 hpi. As shown in Figure 2A, the levels of JA were up at 2 hpi in all treatments, most likely because of the mechanical

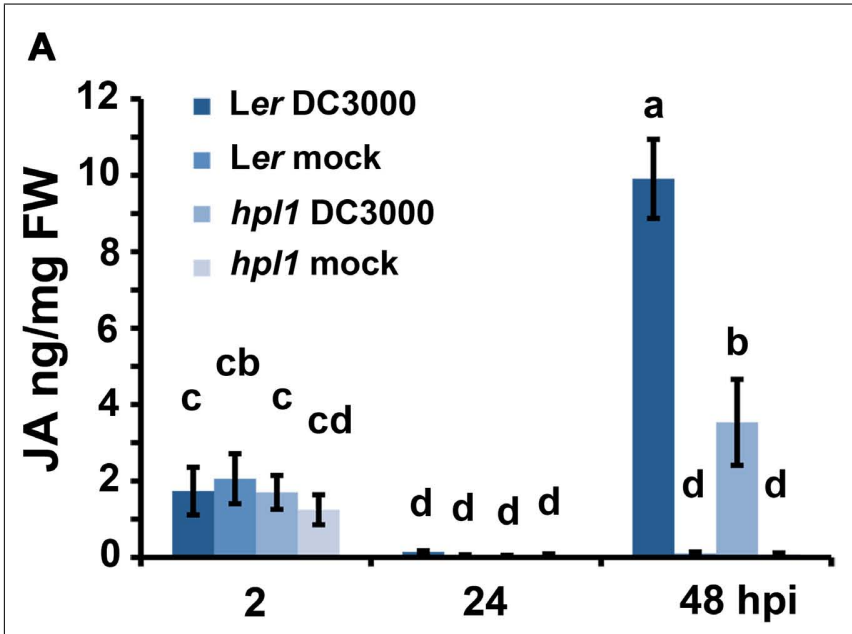

$\mathbf{B}$

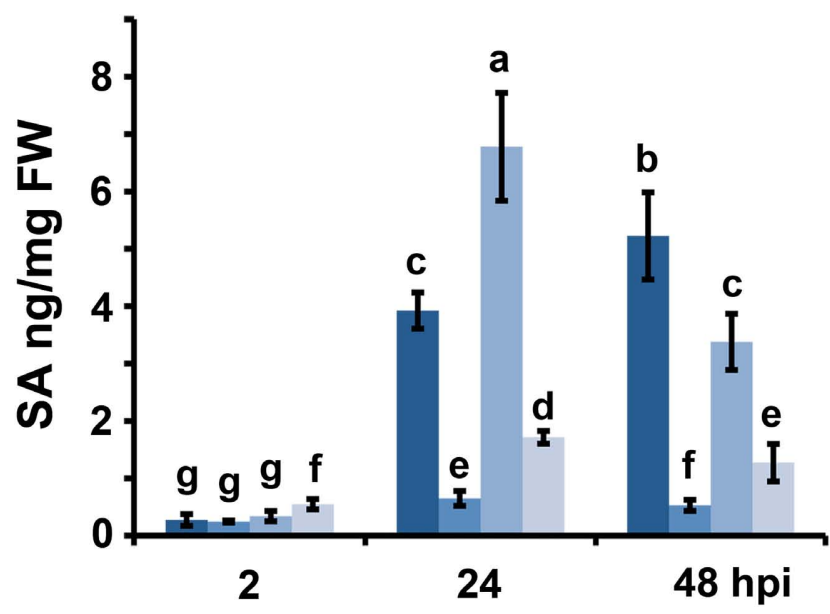

FIGURE 2 | DC3000 infection results in higher JA levels in Ler plants and higher SA levels in hpl1 plants. (A) JA levels in Ler and hp/1 infected with DC3000 at 2, 24, and 48 hpi; (B) SA levels in Ler and hp/1 plants infected with DC3000 at 2, 24, and 48 hpi. In both cases, the hormone levels in the $10 \mathrm{mM} \mathrm{MgSO}_{4}$ (mock) infiltrated plants are also shown. For each timepoint and genotype, nine leaves were harvested, in pools of three from mock-infiltrated or bacteria-infiltrated plants and used for plant hormone quantification. Bars represent the mean of two independent experiments. Error bars represent standard error. Bars annotated with different letters indicate statistically different hormone levels $[P<0.05$, according to analysis of variance (ANOVA), followed by a least significant difference (LSD) post hoc test]. damage caused by the inoculation with the syringe. At $24 \mathrm{hpi}$, this wound response was reset, as JA levels were very low, comparable to the mock inoculation. The situation changed at $48 \mathrm{hpi}$ when JA levels increased in DC3000 infested leaves, in Ler approximately threefold higher than in $h p l 1$. SA levels (Figure 2B) changed already at $24 \mathrm{hpi}$, with levels being approximately 1.7-fold higher in hpll than in Ler, suggesting that SA-related defenses are activated earlier in hpll. In Ler, the SA levels were higher than in $h p l 1$ at 48 hpi suggesting that these defenses are mounted later in Ler.

\section{JA MARKER GENES ARE LESS INDUCED IN hpl1 THAN Ler WHEN INFECTED WITH DC3000}

In order to determine whether the differences in hormone levels had an effect on the expression of relevant marker genes in our system, we performed qRT-PCR for genes downstream of JA and SA. We chose VSP2 and LEC for JA (Potter et al., 1993; Penninckx et al., 1998; Thomma et al., 1998; Liu et al., 2005; Pré et al., 2008) and PR-1 for SA (Bowling et al., 1997; Clarke et al., 2001). PR1 expression was clearly induced by DC3000 at 48 hpi, however, to similar levels in Ler and hpll plants (Figure A1 in Appendix). In contrast, transcript levels of both VSP2 and LEC at 48 hpi (and $24 \mathrm{hpi}$ ) were much lower in $h p l 1$ than in Ler (Figures 3A,B). This result is consistent with the observed lower JA levels in hpll at 48 hpi (Figure 2A).

\section{Ler (HPL) AND hpl1 DIFFER IN THE NUMBER OF DEAD CELLS AND IN CALLOSE DEPOSITION}

To investigate further the differences between Ler and hpll in mounting plant defense responses, we decided to look at the appearance of dead cells and callose deposition. Dead cells are indicative of programed cell death (or the hypersensitive response, HR) and enhanced resistance, usually occurring when an pathogenic effector is recognized by the host (Alfano and Collmer, 1996), whereas callose is typically triggered by conserved pathogen-associated molecular patterns (PAMPs), such as flagellin, at the sites of infection during the relatively early stages of pathogen invasion (Brown etal., 1998; Gómez-Gómez et al., 1999; Jones and Dangl, 2006). Dead cells appeared earlier and more frequently in the more resistant $h p l 1$ while callose deposition occurred earlier and more abundantly in the more susceptible Ler (Figures 4A-C). Dead cells appeared at day 2 in $h p l 1$, whereas in Ler they were not present at all, even at day 3. Ler started to deposit callose massively at day 1 , while much less papillae at this time could be observed in $h p l l$. Moreover, even at later stages of infection, at days 2 and 3, Ler showed more callose deposition than $h p l l$.

\section{E-2-HEXENAL TREATMENT INCREASES SUSCEPTIBILITY TO DC3000}

Since hpll is unable to produce GLVs, we addressed the question whether application of GLVs would restore its susceptibility to DC3000 comparable to Ler. We chose to use the C6-aldehyde E-2-hexenal, one of the most active GLVs, and treated $h p l 1$ and Ler plants with $3 \mu \mathrm{M}$ aerial $E$-2-hexenal or with the carrier methanol $(\mathrm{MeOH})$ for the control treatment. Figure $\mathbf{5 A}$ shows that the treatment with the $\mathrm{C}_{6}$-aldehyde turned both hpl1 and Ler more susceptible to DC3000, as bacterial populations increased about five- and ninefold, respectively, in the E-2-hexenal pre-treated 

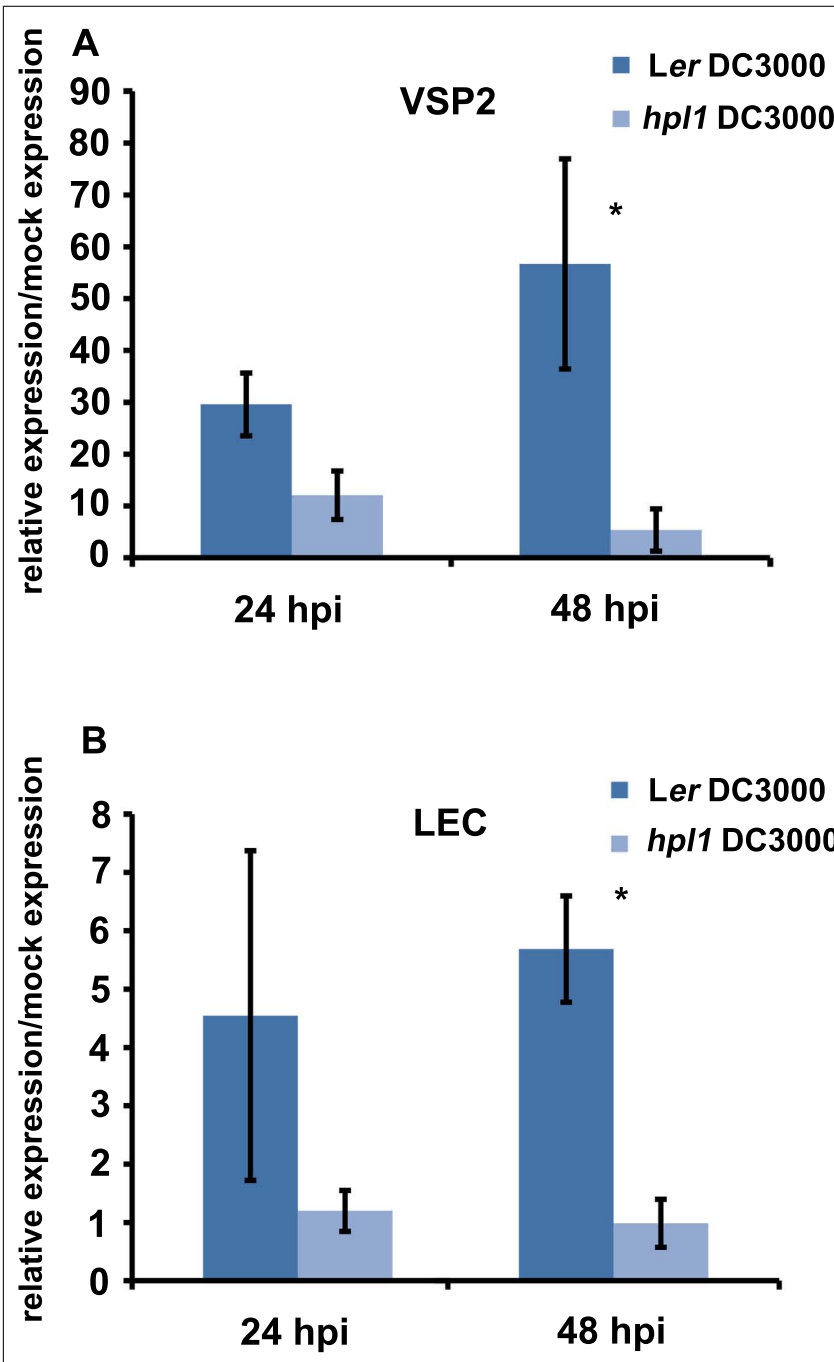

FIGURE 3 | JA-dependent gene expression is higher in infected Ler plants. (A) VSP2 transcript levels and (B) LEC transcript levels were measured by qRT-PCR in Ler and hp/1 infected with DC3000 at 24 and $48 \mathrm{hpi}$ and normalized for SAND transcript levels. Bars represent the ratio between the transcript levels in infected and mock samples. Three infected or mock infiltrated leaves were harvested from three different plants and pooled for RNA isolation. Bars represent the mean of three independent experiments. Error bars represent standard error. Bars annotated with asterisk indicate significant differences among samples $(P<0.05$, according to $t$-test analysis).

leaves compared to the control pre-treatment (Figure 5B). Additionally, we measured JA and SA levels in Ler and hpll plants infected with DC3000 after pre-treatment with E-2-hexenal or $\mathrm{MeOH}$. Although JA and SA levels increased 48 hpi after DC3000 infection, no significant differences in hormone levels were detected between the E-2-hexenal and the control treatment or between Ler and hpll (Figure A2 in Appendix).

\section{THE EFFECT OF E-2-HEXENAL ON BACTERIAL GROWTH ACTS VIA ORA59.}

Since a functional HPL leads to higher susceptibility and higher JA levels upon DC3000 infection and E-2-hexenal pre-treatment

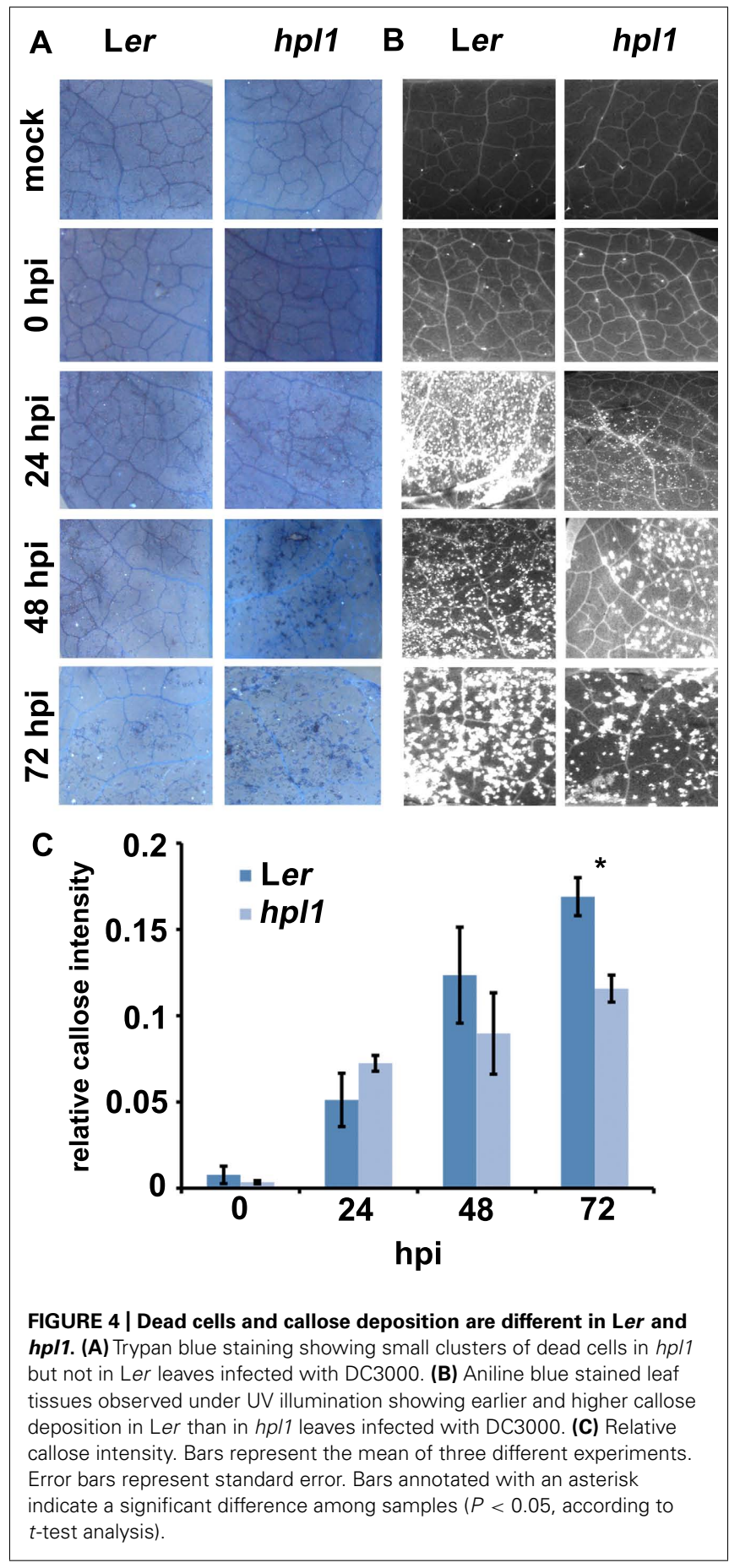

increased susceptibility of Arabidopsis to DC3000 we sought to elucidate part of the signaling pathways involved, by testing if Arabidopsis mutants in the JA-signaling pathway were still more susceptible to DC3000 after treatment with E-2-hexenal. We chose to analyze MYC2 and ORA59 impaired lines since these are the main players in regulating JA-dependent responses and are located in two different branches of the JA-signaling pathway (Lorenzo et al., 2003, 2004; Anderson and Badruzsaufari, 2004; Dombrecht et al., 2007; Oñate-Sánchez et al., 2007; Kazan and Manners, 2008; 


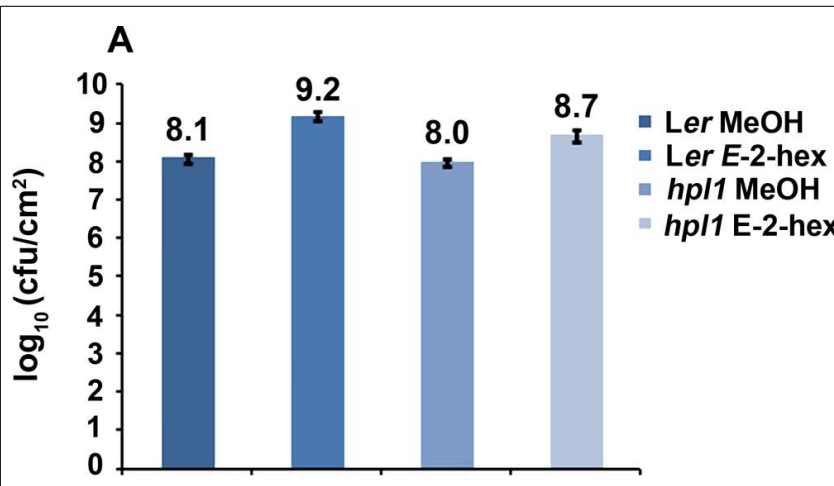

B

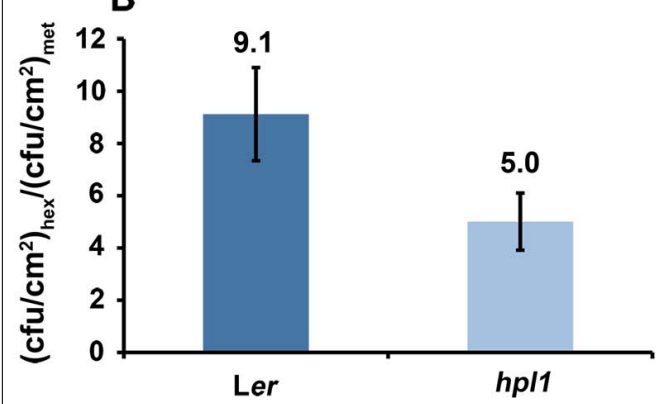

FIGURE 5 | E-2-hexenal pre-treatment increases susceptibility to DC3000. (A) DC3000 populations in Ler and hp/1 pre-treated with $3 \mu \mathrm{M}$ E-2-hexenal or methanol were measured $72 \mathrm{hpi}$. Values are the mean of 16 sets of two leaf disks from 12 plants. Error bars represent standard error. The data presented are from a representative experiment that was repeated four times with similar results. All pre-treatments with $E$-2-hexenal were significantly different from the control treatment ( $P<0.05$, according to Student's $t$-test analysis). (B) Bars represent the ratio between $\mathrm{cfu} / \mathrm{cm}^{2}$ with $E$-2-hexenal pre-treatment and $\mathrm{cfu} / \mathrm{cm}^{2}$ with methanol pre-treatment (control). Values are the mean of three independent experiments. Error bars represent standard error.

Pré et al., 2008). As shown in Figure 6A, myc2 (jin1-7) plants were more resistant to DC3000 as has been reported (FernándezCalvo etal., 2011). Moreover, myc2 as well as wild-type plants showed increased susceptibility to DC3000 when pre-treated with E-2-hexenal, seemingly excluding a role for MYC2 in mediating this phenomenon. In contrast, the same assay performed on RNAi-ORA59 plants (Pré et al., 2008) showed that the bacterial populations increased significantly less in the ORA59 silenced plants compared to the corresponding control line after E-2hexenal treatment (Figure 6B). This indicates an involvement of ORA59 in this response to E-2-hexenal.

\section{THE $E$-2-HEXENAL EFFECT IS CORONATINE DEPENDENT}

Pseudomonas syringae pv. tomato strain DC3000 synthesizes COR (Mitchell, 1982), a phytotoxin that mimics JA-Ile (Thines et al., 2007; Yan et al., 2009), in order to antagonize the SA-dependent defenses (Brooks et al., 2005; Glazebrook, 2005). Therefore, we also determined whether the production of COR was necessary for DC3000 to proliferate more in E-2-hexenal treated plants. For this, Ler and hpll plants were infected with the Pseudomonas syringae mutant strain DC3682 (Ma et al., 1991), that is unable to produce COR, after pre-treatment with E-2-hexenal or methanol. Figure 7

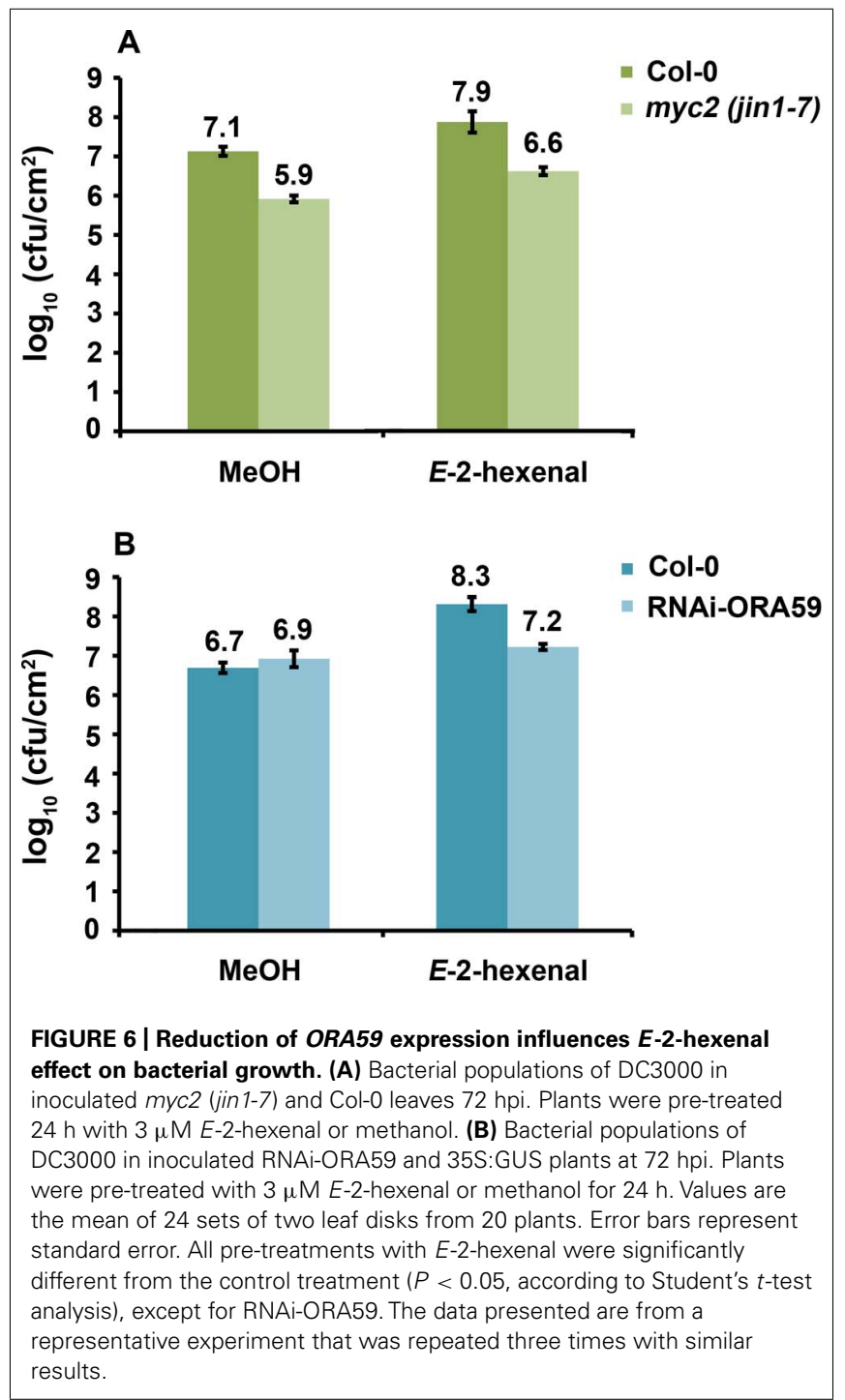

shows that the bacterial populations of the cor mutant were only slightly, but significantly, higher in Ler or hpll plants treated with E-2-hexenal compared to the control plants, but that this increase was much lower than for DC3000 (Figure 1). Thus COR seems to be necessary for DC3000 to benefit from the E-2-hexenal treatment.

\section{DISCUSSION}

Green leaf volatiles have received considerable attention for their ability to induce direct and indirect defense responses in plants and can be considered important players in the already complex network regulated during biotic stress. However the mechanisms by which GLVs influence pathogenesis, and the signaling pathways involved in these responses, are not well known. To address this, we used Ler and its Arabidopsis introgression line, hpll, lacking GLV synthesis, and analyzed their response during infection with the bacterial pathogen Pseudomonas syringae pv. tomato (DC3000). DC3000 was chosen because in some plant species such as lima bean and tobacco, infection triggers E-2-hexenal emission (Croft 


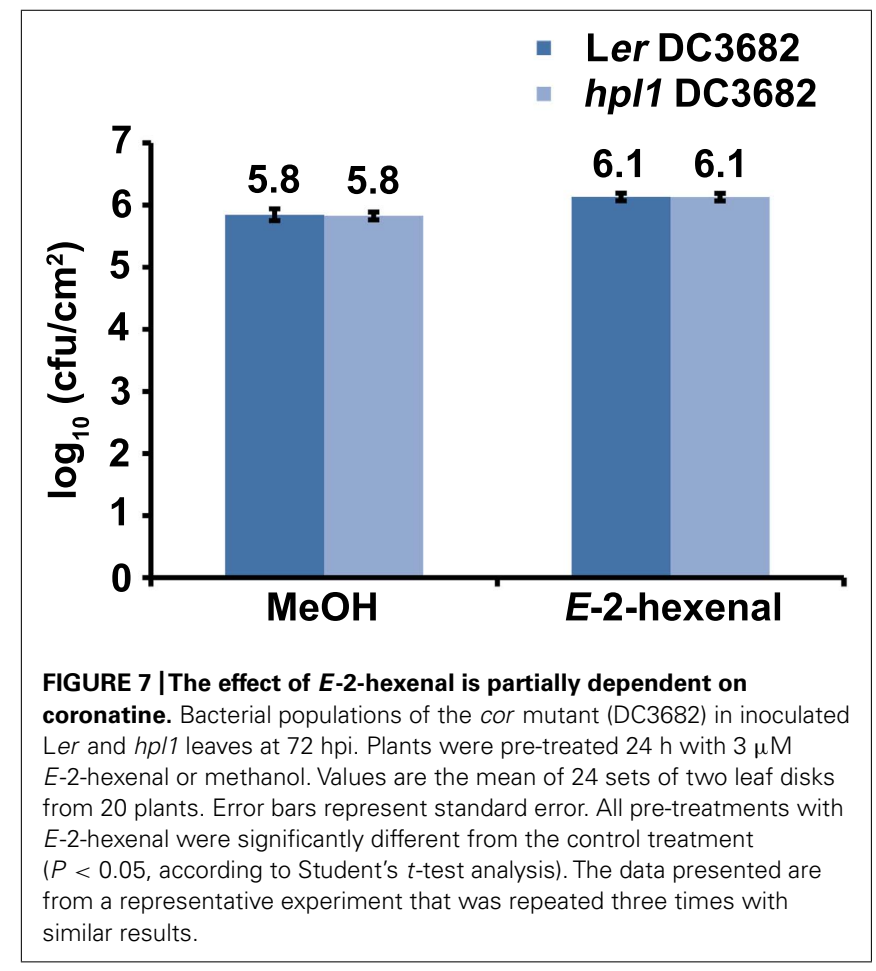

et al., 1993; Heiden et al., 2003). We hypothesized that $h p l 1$ plants would be more susceptible to DC3000 since there is evidence that GLVs and E-2-hexenal have antimicrobial properties (Prost et al., 2005), induce defense-related genes or biosynthesis of defenserelated secondary metabolites (Bate and Rothstein, 1998; Arimura et al., 2001; Gomi et al., 2003; Weber et al., 2004; Farag et al., 2005; Kishimoto et al., 2005, 2006; Paschold et al., 2006), and increase resistance against $B$. cinerea (Kishimoto et al., 2005). However, we found the opposite result: plants impaired in GLV production were more resistant to DC3000 (Figure 1). A similar result was very recently shown in rice where the mutant Oshpl3, not able to synthesize GLVs, was more resistant to Xanthomonas oryzae pv. oryzae (Tong et al., 2012).

Subsequently, we investigated some of the mechanisms underlying this result by analyzing the levels of SA and JA since it is well known that these phytohormones and their antagonism are crucial for the development of pathogenesis in Arabidopsis (Spoel and Dong, 2008; Grant and Jones, 2009; Pieterse et al., 2009). Hormone measurements clearly showed that JA levels were much lower in hpll than in Ler (Figure 2A). Conversely, hpll showed an earlier induction of SA than Ler (Figure 2B). These data suggest that a non-functional HPL gene influences the JA-branch of the oxylipin pathway, leading to lower production of JA when Arabidopsis is challenged with Pseudomonas. Thus, this is not related to substrate competition as previously shown in Arabidopsis where ectopic expression of HPL led to lower JA levels upon wounding (Chehab et al., 2006). Reduction of HPL expression in rice and N. attenuata also influenced JA levels but differently: Oshpl3 and asHPL1 had increased JA levels (Halitschke et al., 2004; Tong et al., 2012), in N. attenuata probably due to crosstalk between the GLV and JA pathway (Allmann et al., 2010).
Since JA-signaling downstream of COI1 occurs via two different branches, regulated by MYC2 or ORA59, we used markers for both branches to study their activation after DC3000 infection. $L E C$, a lectin-like gene, was used for the ORA59 pathway since it is induced by methyl-jasmonate and upon ORA59 overexpression (Schenk et al., 2000; Pré et al., 2008), while VSP2 was used for the MYC2 pathway (Abe et al., 2003; Dombrecht et al., 2007). Both VSP2 and LEC transcript levels were much lower in $h p l 1$ than in Ler (Figures 3A,B) concurrent with the lower JA levels. Thus DC3000 activates in Ler, with an active HPL unlike Col-0 (Duan et al., 2005), with which most DC3000 experiments are carried out, both branches of the JA-signaling pathway and antagonistic control of these distinct branches of the JA pathway (Verhage et al., 2011) is apparently minor. Transcript levels of the SA-marker $P R-1$ were higher upon DC3000 infection, similarly in hpll and Ler (Figure A1 in Appendix), probably because the differences in SA levels between the two genotypes were not big enough to cause a difference. Thus it seems that the lower JA levels in hpl1 plants leads to less activation of the JA-signaling pathways and renders them less susceptible to DC3000.

A hallmark of basal plant defenses to pathogen infection is the deposition of callose. PAMP-induced callose deposition has recently been defined with essential roles for the DC3000 type III effector HopM1 and COR suppressing callose deposition, the latter being, interestingly, partly COI1-independent (Geng et al., 2012). Our results showed that in hpll, although with smaller bacterial populations than in Ler, clearly less callose was deposited (Figures 4B,C). Ethylene (ET) signaling it is crucial for callose deposition in response to flagellin (Clay et al., 2009). It is possible that this ET signaling is less activated in $h p l 1$, leading to less callose deposition. Support for this comes from our complementation studies with the hpl1 mutant, a response that is largely dependent on ORA59, a TF that integrates JA and ET signaling (Figure 6B). Perhaps related to this is the fact that DC3000 is apparently less effective in preventing cell death in $h p l 1$ than in Ler (Figure 4A), with fewer living cells producing less callose. DC3000 apparently triggers in hpll a higher rate of cell death, which is related to higher resistance (Jones and Dangl, 2006).

With the aim to overcome the hpll phenotype in response to DC3000 infection, we decided to treat these, and Ler, plants with E-2-hexenal. The pre-treatment with $3 \mu \mathrm{M} E$-2-hexenal for $24 \mathrm{~h}$ prior to DC3000 infection made hpl1 plants considerably more susceptible to DC3000 (Figures 5A,B). The increase in bacterial populations was about ninefold in Ler and fivefold in $h p l 1$ plants. Thus Ler plants remained more susceptible to DC3000 than hpll plants, most likely due to the functional HPL. Due to its high reactivity for being a reactive electrophile species (RES), E-2-hexenal, either induced during the HR or exogenously applied, can undergo conjugation to glutathione (GSH), leading to the formation of E-2hexenal-GSH adducts in the form of 1-hexanol-3-GSH (Davoine et al., 2006; Mirabella etal., 2008). Conjugation to GSH is a well-known mechanism to inactivate reactive molecules (Coleman et al., 1997). Additionally, conjugation to cellular proteins has been reported to occur for several RES, including E-2-hexenal (Davoine et al., 2006; Myung et al., 2007; Dueckershoff et al., 2008; Mueller et al., 2008; Yamauchi et al., 2008). Therefore, we cannot exclude the possibility that, through conjugation, E-2-hexenal affects the 
function of proteins involved in the plant defense responses to DC3000, making Arabidopsis more susceptible to this pathogen. A similar effect has been reported for syringolin, a toxin with an unsaturated $\alpha, \beta$ carbonyl moiety, that makes it a RES, produced by, e.g., Pseudomonas syringae pv. syringae. This toxin specifically inhibits the proteasome in order to suppress host defenses (Groll et al., 2008; Schellenberg et al., 2010).

Analyses of phytohormone levels after treatment of E-2hexenal and DC3000 infection showed that there were no statistically significant differences in SA and JA levels between control and treatment (Figure A2 in Appendix). So far only in monocots (maize) an increase in JA has been measured after a GLV treatment (Engelberth etal., 2004; Engelberth, 2011). In the JA-signaling pathway COI1 plays a central role and mutants in this gene are blocked in almost all JA responses (Feng et al., 2003; Devoto et al., 2005; Wang et al., 2008). Downstream of COI1, different TFs regulate specific JA-dependent responses: MYC2 and ORA59 are the main players involved. The MYC2-dependent branch is associated with wound response, responses against herbivores and is also regulated by abscisic acid (ABA; Lorenzo et al., 2003). This basic helix-loop-helix (bHLH) transcription factor regulates a large number of JA-responsive genes (Dombrecht et al., 2007), among which VEGETATIVE STORAGE PROTEIN2 (VSP2; Liu et al., 2005). In the other branch, ORA59 integrates JA and ET signaling (Pré et al., 2008). Interestingly, in spite of the absence of difference in JA and SA levels, the higher susceptibility of Arabidopsis plants to DC3000 after E-2-hexenal treatment was dependent on ORA59. The DC3000 bacterial populations increased only slightly in ir-ORA59 plants after E-2-hexenal treatment as compared to

\section{REFERENCES}

Abe, H., Urao, T., Ito, T., and Seki, M. (2003). Arabidopsis AtMYC2 (bHLH) and AtMYB2 (MYB) function as transcriptional activators in abscisic acid signaling. Plant Cell 15, 63-78.

Alfano, J. R., and Collmer, A. (1996). Bacterial pathogens in plants: life up against the wall. Plant Cell 8, 1683-1698.

Allmann, S., Halitschke, R., Schuurink, R. C., and Baldwin, I. T. (2010). Oxylipin channelling in Nicotiana attenuata: lipoxygenase 2 supplies substrates for green leaf volatile production. Plant Cell Environ. 33, 2028-2040.

Anderson, J., and Badruzsaufari, E. (2004). Antagonistic interaction between abscisic acid and jasmonateethylene signaling pathways modulates defense gene expression and disease resistance in. Plant Cell 16, 3460-3479.

Arimura, G., Ozawa, R., Horiuchi, J., Nishioka, T., and Takabayashi, J. (2001). Plant-plant interactions mediated by volatiles emitted from plants infested by spider mites. Biochem. Syst. Ecol. 29, 1049-1061.

Arimura, G., Ozawa, R., Shimoda, T., Nishioka, T., Boland, W., and
Takabayashi, J. (2000). Herbivoryinduced volatiles elicit defence genes in lima bean leaves. Nature 406, 512-515.

Bate, N. J., and Rothstein, S. J. (1998). C6-volatiles derived from the lipoxygenase pathway induce a subset of defense-related genes. Plant J. 16 , 561-569. rieri, E., Pickett, J. A., Wadhams, L. J., and Yasuda, T. (2003). Volatiles from whitefly-infested plants elicit a hostlocating response in the parasitoid, Encarsia formosa. J. Chem. Ecol. 29 , 1589-1600.

Block, A., Schmelz, E., Jones, J. B., and Klee, H. J. (2005). Coronatine and salicylic acid: the battle between Arabidopsis and Pseudomonas for phytohormone control. Mol. Plant Pathol. 6, 79-83.

Bowling, S. A., Clarke, J. D., Liu, Y., Klessig, D. F., and Dong, X. (1997). The cpr5 mutant of Arabidopsis expresses both NPR1-dependent and NPR1-independent resistance. Plant Cell 9, 1573-1584.

Brooks, D. M. D., Bender, C. L. C., and Kunkel, B. N. B. (2005). The Pseudomonas syringae phytotoxin coronatine promotes virulence by
Birkett, M. A., Chamberlain, K., Guer-

control (35S-GUS) plants (Figure 6B), indicating the relevance of JA signaling, and perhaps ET signaling. A role for MYC2 in this process was excluded based on the fact that myc2 mutants still responded to exogenous E-2-hexenal treatment (Figure 6A).

From the bacterial side we investigated whether the production of COR was necessary to benefit from the E-2-hexenal treatment. For this we employed cor, a COR-deficient strain, to infect plants, after the E-2-hexenal or control treatment. The result showed that there was a small but significant increase in bacterial populations of the cor strain after the E-2-hexenal treatment (Figure 7). Nevertheless this difference was much smaller than for DC3000, suggesting that COR is necessary for DC3000 to fully benefit from GLVs.

Our data show that a functional HPL in Arabidopsis promotes susceptibility to DC3000. This effect is partially mediated by ORA59 in the plant and by COR in the bacteria.

The question remains how DC3000 precisely exploits HPL or its products, GLVs or the $\mathrm{C}_{12}$ compounds that are also formed in the HPL pathway (Kallenbach et al., 2011), for its benefit. Since it is clear that some herbivores can lower HPL transcript levels (Halitschke et al., 2004; Savchenko et al., 2012), we propose that HPL may be a target for DC3000 to employ in Arabidopsis, albeit to its own advantage.

\section{ACKNOWLEDGMENTS}

We kindly acknowledge Johan Memelink (Leiden University, Netherlands) for providing the ir-ORA59 seeds and Saskia van Wees (University of Utrecht, Netherlands) for $m y c 2$ seeds. Alessandra Scala was supported by NWO-ALW grant 818.02.017.

overcoming salicylic acid-dependent defences in Arabidopsis thaliana. Mol. Plant Pathol. 6, 629-639.

Brown, I., Trethowan, J., and Kerry, M. (1998). Localization of components of the oxidative cross-linking of glycoproteins and of callose synthesis in papillae formed during the interaction between non-pathogenic strains of Xanthomonas campestris and French bean mesophyll cells. Plant J. 15, 333-343.

Chehab, E., Raman, G., and Walley, J. (2006). Rice HYDROPEROXIDE LYASES with unique expression patterns generate distinct aldehyde signatures in Arabidopsis. Plant Physiol. 141, 121-134.

Clarke, J. D., Aarts, N., Feys, B. J., Dong, X., and Parker, J. E. (2001). Constitutive disease resistance requires EDS1 in the Arabidopsis mutants cpr1 and cpr6 and is partially EDS1dependent in cpr5. Plant J. 26, 409-420.

Clay, N., Adio, A., and Denoux, C. (2009). Glucosinolate metabolites required for an Arabidopsis innate immune response. Science 323, 95-101.

Coleman, J. O. D., Randall, R., and Blake-Kalff, M. M. A. (1997).
Detoxification of xenobiotics in plant cells by glutathione conjugation and vacuolar compartmentalization: a fluorescent assay using monochlorobimane. Plant Cell Environ. 20, 449-460.

Croft, K., Juttner, F., and Slusarenko, A. (1993). Volatile products of the lipoxygenase pathway evolved from Phaseolus vulgaris (L.) leaves inoculated with Pseudomonas syringae pv phaseolicola. Plant Physiol. 101, 13-24.

Cuppels, D. A. (1986). Generation and characterization of Tn5 insertion mutations in. Appl. Environ. Microbiol. 51, 323-327.

Czechowski, T., Stitt, M., and Altmann, T. (2005). Genome-wide identification and testing of superior reference genes for transcript normalization in Arabidopsis. Plant Physiol. 139, 5-17.

Davoine, C., Falletti, O., Douki, T., Iacazio, G., Ennar, N., Montillet, J. L., et al. (2006). Adducts of oxylipin electrophiles to glutathione reflect a 13 specificity of the downstream lipoxygenase pathway in the tobacco hypersensitive response. Plant Physiol. 140, 1484-1493.

de Torres Zabala, M., Bennett, M. H., Truman, W. H., and Grant, M. 
R. (2009). Antagonism between salicylic and abscisic acid reflects early host-pathogen conflict and moulds plant defence responses. Plant J. 59, 375-386.

Devoto, A., Ellis, C., Magusin, A., Chang, H.-S., Chilcott, C., Zhu, T., etal. (2005). Expression profiling reveals COIl to be a key regulator of genes involved in woundand methyl jasmonate-induced secondary metabolism, defence, and hormone interactions. Plant Mol. Biol. 58, 497-513.

Dombrecht, B., Xue, G. P., Sprague, S. J., Kirkegaard, J. A., Ross, J. J., Reid, J. B., et al. (2007). MYC2 differentially modulates diverse jasmonatedependent functions in Arabidopsis. Plant Cell 19, 2225-2245.

Duan, H., Huang, M., Palacio, K., and Schuler, M. (2005). Variations in CYP74B2 (hydroperoxide lyase) gene expression differentially affect hexenal signaling in the Columbia and Landsberg erecta ecotypes of Arabidopsis. Plant Physiol. 139, 15291544.

Dueckershoff, K., Mueller, S., Mueller, M. J., and Reinders, J. (2008). Impact of cyclopentenone-oxylipins on the proteome of Arabidopsis thaliana. Biochim. Biophys. Acta 1784, 19751985.

Engelberth, J. (2011). Selective inhibition of jasmonic acid accumulation by a small $\alpha, \beta$-unsaturated carbonyl and phenidone reveals different modes of octadecanoid signalling activation in response to insect elicitors and green leaf volatiles in $\mathrm{Zea}$ mays. BMC Res. Notes 4:377. doi: 10.1186/1756-0500-4-377

Engelberth, J., Alborn, H. T., Schmelz, E. A., and Tumlinson, J. H. (2004). Airborne signals prime plants against insect herbivore attack. Proc. Natl. Acad. Sci. U.S.A. 101, 1781-1785.

Fall, R., Karl, T., Hansel, A., Jordan, A., and Lindiger, W. (1999). Volatile organic compounds emitted after leaf wounding: on-line analysis by proton-transfer-reaction mass spectrometry. J. Geophys. Res. Atmos. 104, 15963-15974.

Farag, M. A., Fokar, M., Abd, H., Zhang, H., Allen, R. D., and Paré, P. W. (2005). (Z)-3-hexenol induces defense genes and downstream metabolites in maize. Planta 220, 900-909.

Farag, M. A., and Paré, P. W. (2002). C6green leaf volatiles trigger local and systemic VOC emissions in tomato. Phytochemistry 61, 545-554.

Farmer, E. E., and Davoine, C. (2007). Reactive electrophile species. Curr. Opin. Plant Biol. 10, 380-386.
Feng, S., Ma, L., and Wang, X. (2003). The $\mathrm{COP}_{9}$ signalosome interacts physically with $\mathrm{SCF}^{\mathrm{CO} 1}$ and modulates jasmonate responses. Plant Cell 15, 1083-1094.

Fernández-Calvo, P., Chini, A. Fernández-Barbero, G., Chico, J.M., Gimenez-Ibanez, S., Geerinck, J. et al. (2011). The Arabidopsis bHLH transcription factors MYC3 and MYC4 are targets of JAZ repressors and act additively with MYC2 in the activation of jasmonate responses. Plant Cell 23, 701-715

Frost, C. J., Appel, H. M., Carlson, J. E., De Moraes, C. M., Mescher, M. C., and Schultz, J. C. (2007). Within-plant signalling via volatiles overcomes vascular constraints on systemic signalling and primes responses against herbivores. Ecol. Lett. 10, 490-498.

Frost, C. J., Mescher, M. C., Carlson, J. E., and De Moraes, C. M. (2008). Plant defense priming against herbivores: getting ready for a different battle. Plant Physiol. 146, 818-824

Geng, X., Cheng, J., Gangadharan, A. and Mackey, D. (2012). The coronatine toxin of Pseudomonas syringae is a multifunctional suppressor of Arabidopsis defense. Plant Cell 24 4763-4774.

Glazebrook, J. (2005). Contrasting mechanisms of defense against biotrophic and necrotrophic pathogens. Annu. Rev. Phytopathol. 43, 205-227.

Gómez-Gómez, L., Felix, G., and Boller, T. (1999). A single locus determines sensitivity to bacterial flagellin in Arabidopsis thaliana. Plant J. 18, 277-284.

Gomi, K., Satoh, M., Ozawa, R., Shinonaga, Y., Sanada, S., Sasaki, K., et al. (2010). Role of hydroperoxide lyase in white-backed planthopper (Sogatella furcifera Horváth)-induced resistance to bacterial blight in rice, Oryza sativa L. Plant J. 61, 46-57.

Gomi, K., Yamasaki, Y., Yamamoto, H., and Akimitsu, K. (2003). Characterization of a hydroperoxide lyase gene and effect of C6-volatiles on expression of genes of the oxylipin metabolism in Citrus. J. Plant Physiol. 160, 1219-1231.

Gouinguené, S., Pickett, J. A., Wadhams L. J., Birkett, M. A., and Turlings, T C. J. (2005). Antennal electrophysiological responses of three parasitic wasps to caterpillar-induced volatiles from maize (Zea mays mays), cotton (Gossypium herbaceum), and cowpea (Vigna unguiculata). J. Chem. Ecol. 31, 1023-1038.
Grant, M. R., and Jones, J. D. G. (2009). Hormone (dis)harmony moulds plant health and disease. Science 324, 750-752.

Groll, M., Schellenberg, B., Bachmann, A. S., Archer, C. R., Huber, R., Powell, T. K., etal. (2008). A plant pathogen virulence factor inhibits the eukaryotic proteasome by a novel mechanism. Nature 452, 755-758.

Halitschke, R., Ziegler, J., Keinänen, M. and Baldwin, I. T. (2004). Silencing of hydroperoxide lyase and allene oxide synthase reveals substrate and defense signaling crosstalk in Nicotiana attenuata. Plant J. 40, 35-46.

Heiden, A. C., Kobel, K., Langebartels, C., Schuh-Thomas, G., and Wildt, J. (2003). Emissions of oxygenated volatile organic compounds from plants part I: emissions from lipoxygenase activity. J. Atmos. Chem. 45, 143-172.

Heil, M., and Silva Bueno, J. C. (2007). Within-plant signaling by volatiles leads to induction and priming of an indirect plant defense in nature. Proc. Natl. Acad. Sci. U.S.A. 104, 5467-5472.

Hirano, S. S., and Upper, C. D. (2000). Bacteria in the leaf ecosystem with emphasis on Pseudomonas syringae a pathogen, ice nucleus, and epiphyte. Microbiol. Mol. Biol. Rev. 64, 624-653.

Hong, S. M., Bahn, S. C., Lyu, A., Jung, H. S., and Ahn, J. H. (2010). Identification and testing of superior reference genes for a starting pool of transcript normalization in Arabidopsis. Plant Cell Physiol. 51, 1694-1706.

Jones, J. D. G., and Dangl, J. L. (2006). The plant immune system. Nature 444, 323-329.

Kallenbach, M., Gilardoni, P. A., Allmann, S., Baldwin, I. T., and Bonaventure, G. (2011). C12 derivatives of the hydroperoxide lyase pathway are produced by product recycling through lipoxygenase- 2 in Nicotiana attenuata leaves. New Phy tol. 191, 1054-1068.

Kazan, K., and Manners, J. M. (2008). Jasmonate signaling: toward an integrated view. Plant Physiol. 146, 14591468.

Kessler, A., and Baldwin, I. T. (2001). Defensive function of herbivoreinduced plant volatile emissions in nature. Science 291, 21412144.

Kessler, A., Halitschke, R., Diezel, C. and Baldwin, I. T. (2006). Priming of plant defense responses in nature by airborne signaling between Artemisia tridentata and Nicotiana attenuata. Oecologia 148, 280-292.
King, E. O., Ward, M. K., and Raney, D. E. (1954). Two simple media for the demonstration of phycocyanin and fluorescin. J. Lab. Clin. Med. 44, 301-307.

Kishimoto, K., Matsui, K., Ozawa, R., and Takabayashi, J. (2005). Volatile C6-aldehydes and Allo-ocimene activate defense genes and induce resistance against Botrytis cinerea in Arabidopsis thaliana. Plant Cell Physiol. 46, 1093-1102.

Kishimoto, K., Matsui, K., Ozawa, R., and Takabayashi, J. (2006). ETR1-, JAR1- and PAD2-dependent signaling pathways are involved in C6aldehyde-induced defense responses of Arabidopsis. Plant Sci. 171, 415-423.

Liu, Y., Ahn, J., Datta, S., and Salzman, R. (2005). Arabidopsis vegetative storage protein is an anti-insect acid phosphatase. Plant Physiol. 139, 1545-1556.

Lorenzo, O., Chico, J., Sánchez-Serrano, J. J., and Solano, R. (2004). JASMONATE-INSENSITIVE1 encodes a MYC transcription factor essential to discriminate between different jasmonate-regulated defense responses in Arabidopsis. Plant Cell 16, 1938-1950.

Lorenzo, O., Piqueras, R., SánchezSerrano, J. J., and Solano, R. (2003). ETHYLENE RESPONSE FACTOR1 integrates signals from ethylene and jasmonate pathways in plant defense. Plant Cell 15, 165-178.

Luna, E., Pastor, V., Robert, J., Flors, V., Mauch-Mani, B., and Ton, J. (2011). Callose deposition: a multifaceted plant defense response. Mol. Plant Microbe Interact. 24, 183-193.

Ma, S.-W., Morris, V. L., and Cuppels, D. A. (1991). Characterization of a DNA region required for production of the phytotoxin coronatine by Pseudomonas syringae pv. tomato. Mol. Plant Microbe Interact. 4, 69-74.

Mirabella, R., Rauwerda, H., Struys, E. A., Jakobs, C., Triantaphylidès, C., Haring, M. A., et al. (2008). The Arabidopsis herl mutant implicates GABA in E-2-hexenal responsiveness. Plant J. 53, 197-213.

Mitchell, R. (1982). Coronatine production by some phytopathogenic pseudomonads. Physiol. Plant Pathol. 20, 83-89.

Mueller, S., Hilbert, B., Dueckershoff, K., Roitsch, T., Krischke, M., Mueller, M. J., et al. (2008). General detoxification and stress responses are mediated by oxidized lipids through TGA transcription factors in Arabidopsis. Plant Cell 20, 768-785.

Myung, K., Hamilton-Kemp, T. R., and Archbold, D. D. (2007). Interaction 
with and effects on the profile of proteins of Botrytis cinerea by $\mathrm{C} 6$ aldehydes. J. Agric. Food Chem. 55, 2182-2188.

Oñate-Sánchez, L., Anderson, J. P., Young, J., and Singh, K. B. (2007). AtERF14, a member of the ERF family of transcription factors, plays a nonredundant role in plant defense. Plant Physiol. 143, 400-409.

Park, D. H., Mirabella, R., Bronstein, P. A., Preston, G. M., Haring, M. A., Lim, C. K., etal. (2010). Mutations in gamma-aminobutyric acid (GABA) transaminase genes in plants or Pseudomonas syringae reduce bacterial virulence. Plant J. 64, 318-330.

Paschold, A., Halitschke, R., and Baldwin, I. T. (2006). Using 'mute' plants to translate volatile signals. Plant J. 45, 275-291.

Penninckx, I. A., Thomma, B. P., Buchala, A., Métraux, J. P., and Broekaert, W. F. (1998). Concomitant activation of jasmonate and ethylene response pathways is required for induction of a plant defensin gene in Arabidopsis. Plant Cell 10, 2103-2113.

Pfaffl, M. W. (2001). A new mathematical model for relative quantification in real-time RT-PCR. Nucleic Acids Res. 29, e45.

Pieterse, C. M. J., Leon-Reyes, A., Van der Ent, S., and Van Wees, S. C. M. (2009). Networking by smallmolecule hormones in plant immunity. Nat. Chem. Biol. 5, 308-316.

Potter, S., Uknes, S., and Lawton, K. (1993). Regulation of a heveinlike gene in Arabidopsis. Mol. Plant Microbe Interact. 6, 680-685.

Pré, M., Atallah, M., Champion, A., De Vos, M., Pieterse, C. M. J., and Memelink, J. (2008). The AP2/ERF domain transcription factor ORA59 integrates jasmonic acid and ethylene signals in plant defense. Plant Physiol. 147, 1347-1357.

Prost, I., Dhondt, S., and Rothe, G. (2005). Evaluation of the antimicrobial activities of plant oxylipins supports their involvement in defense against pathogens. Plant Physiol. 139, 1902-1913.

Ruther, J., and Fürstenau, B. (2005). Emission of herbivore-induced volatiles in absence of a herbivore response of Zea mays to green leaf volatiles and terpenoids. $Z$. Naturforsch. C 60, 743-756.

Ruther, J., and Kleier, S. (2005). Plantplant signaling: ethylene synergizes volatile emission in Zea mays induced by exposure to (Z)-3-hexen-1-ol. J. Chem. Ecol. 31, 2217-2222.

Savchenko, T., Pearse, I., and Ignatia, L. (2012). Insect herbivores selectively suppress the HPL branch of the oxylipin pathway in host plants. Plant J. 73, 653-662.

Schellenberg, B., Ramel, C., and Dudler, R. (2010). Pseudomonas syringae virulence factor syringolin A counteracts stomatal immunity by proteasome inhibition. Mol. Plant Microbe Interact. 23, 1287-1293.

Schenk, P. M., Kazan, K., Wilson, I., Anderson, J. P., Richmond, T. Somerville, S. C., et al. (2000). Coordinated plant defense responses in Arabidopsis revealed by microarray analysis. Proc. Natl. Acad. Sci. U.S.A. 97, 11655-11660.

Shiojiri, K., Kishimoto, K., Ozawa, R., Kugimiya, S., Urashimo, S., Arimura, G., et al. (2006a). Changing green leaf volatile biosynthesis in plants: an approach for improving plant resistance against both herbivores and pathogens. Proc. Natl. Acad. Sci. U.S.A. 103, 16672-16676.

Shiojiri, K., Ozawa, R., Matsui, K., Kishimoto, K., Kugimiya, S., and Takabayashi, J. (2006b). Role of the lipoxygenase/lyase pathway of hostfood plants in the host searching behavior of two parasitoid species, Cotesia glomerata and Cotesia plutellae. J. Chem. Ecol. 32, 969-979.

Shiojiri, K., Ozawa, R., Matsui, K., Sabelis, M. W., and Takabayashi, J. (2012). Intermittent exposure to traces of green leaf volatiles triggers a plant response. Sci. Rep. 2, 378.

Shiojiri, K., Takabayashi, J., Yano, S., and Takafuji, A. (2000). Flight response of parasitoids toward plant-herbivore complexes: a comparative study of two parasitoid-herbivore systems on cabbage plants. Appl. Entomol. Zool. 35, 87-92.

Spoel, S. H., and Dong, X. (2008). Making sense of hormone crosstalk during plant immune responses. Cell Host Microbe 3, 348-351.

Thines, B., Katsir, L., Melotto, M., Niu, Y., Mandaokar, A., Liu, G., et al. (2007). JAZ repressor proteins are targets of the SCF(COI1) complex during jasmonate signalling. Nature 448, 661-665.

Thomma, B. P., Eggermont, K., Penninckx, I. A., Mauch-Mani, B. Vogelsang, R., Cammue, B. P., et al. (1998). Separate jasmonatedependent and salicylate-dependent defense-response pathways in Arabidopsis are essential for resistance to distinct microbial pathogens. Proc. Natl. Acad. Sci. U.S.A. 95, $15107-$ 15111.

Tong, X., Qi, J., Zhu, X., Mao, B., Zeng, L., Wang, B., et al. (2012). The rice hydroperoxide lyase OsHPL3 functions in defense responses by modulating the oxylipin pathway. Plant $J$. 71, 763-775.

Turlings, T., Loughrin, J., McCall, P. J. Röse, U. S., Lewis, W. J., and Tumlinson, J. H. (1995). How caterpillardamaged plants protect themselves by attracting parasitic wasps. Proc. Natl. Acad. Sci. U.S.A. 92, 41694174.

Verhage, A., Vlaardingerbroek, I., Raaymakers, C., Van Dam, N. M., Dicke, M., Van Wees, S. C. M., et al. (2011). Rewiring of the jasmonate signaling pathway in Arabidopsis during insect herbivory. Front. Plant Sci. 2:47. doi: 10.3389/fpls.2011.00047

Wang, L., Mitra, R. M., Hasselmann, K. D., Sato, M., LenarzWyatt, L., Cohen, J. D., et al. (2008) The genetic network controlling the Arabidopsis transcriptional response to Pseudomonas syringae pv. mac ulicola: roles of major regulators and the phytotoxin coronatine. $\mathrm{Mol}$. Plant Microbe Interact. 21, 14081420.

Weber, H., Chételat, A., Reymond, P., and Farmer, E. E. (2004). Selective and powerful stress gene expression in Arabidopsis in response to malondialdehyde. Plant J. 37, 877-888.

Whalen, M. C., Innes, R. W., Bent, A. F., and Staskawicz, B. J. (1991). Identification of Pseudomonas syringae pathogens of Arabidopsis and a bacterial locus determining avirulence on both Arabidopsis and soybean. Plant Cell 3, 49-59.

Yamauchi, Y., Furutera, A., Seki, K., Toyoda, Y., Tanaka, K., and Sugimoto, Y. (2008). Malondialdehyde generated from peroxidized linolenic acid causes protein modification in heat-stressed plants. Plant Physiol. Biochem. 46, 786-793.

Yan, J., Zhang, C., Gu, M., Bai, Z., Zhang, W., Qi, T., et al. (2009). The Arabidopsis CORONATINE INSENSITIVE1 protein is a jasmonate receptor. Plant Cell 21, 22202236.

Yan, Z., and Wang, C. (2006). Woundinduced green leaf volatiles cause the release of acetylated derivatives and a terpenoid in maize. Phytochemistry 67, 34-42.

Zeringue, H. J. (1992). Effects of C6$\mathrm{C} 10$ alkenals and alkanals on eliciting a defence response in the developing cotton boll. Phytochemistry 31, 6-9.

Conflict of Interest Statement: The authors declare that the research was conducted in the absence of any commercial or financial relationships that could be construed as a potential conflict of interest.

Received: 21 December 2012; accepted: 15 March 2013; published online: 12 April 2013.

Citation: Scala A, Mirabella $R$, Mugo C, Matsui K, Haring MA and Schuurink RC (2013) E-2-hexenal promotes susceptibility to Pseudomonas syringae by activating jasmonic acid pathways in Arabidopsis. Front. Plant Sci. 4:74. doi: 10.3389/fpls.2013.00074

This article was submitted to Frontiers in Plant-Microbe Interaction, a specialty of Frontiers in Plant Science.

Copyright (C) 2013 Scala, Mirabella, Mugo, Matsui, Haring and Schuurink. This is an open-access article distributed under the terms of the Creative Commons Attribution License, which permits use, distribution and reproduction in other forums, provided the original authors and source are credited and subject to any copyright notices concerning any thirdparty graphics etc. 


\section{APPENDIX}

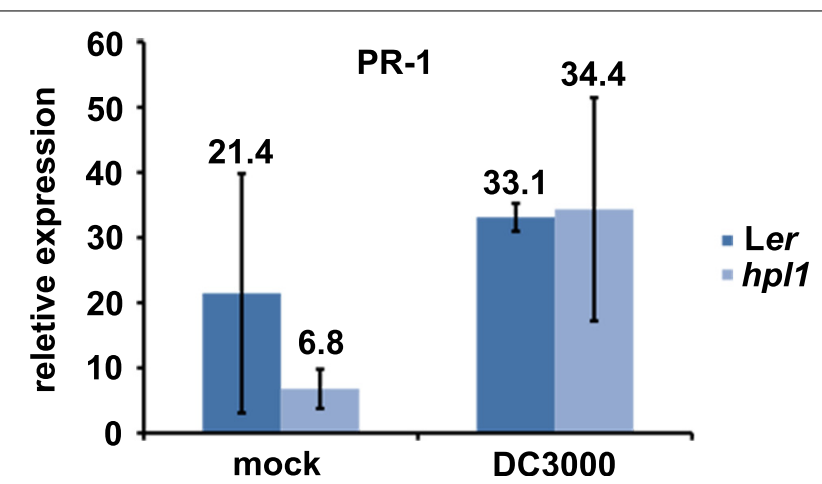

FIGURE A1 | PR-1 expression is equally induced in Ler and hpl1. PR-1 transcript levels were measured by qRT-PCR in Ler and $h p / 1$ infected with DC3000 48 hpi and normalized for SAND transcript levels. Error bars represent standard error.

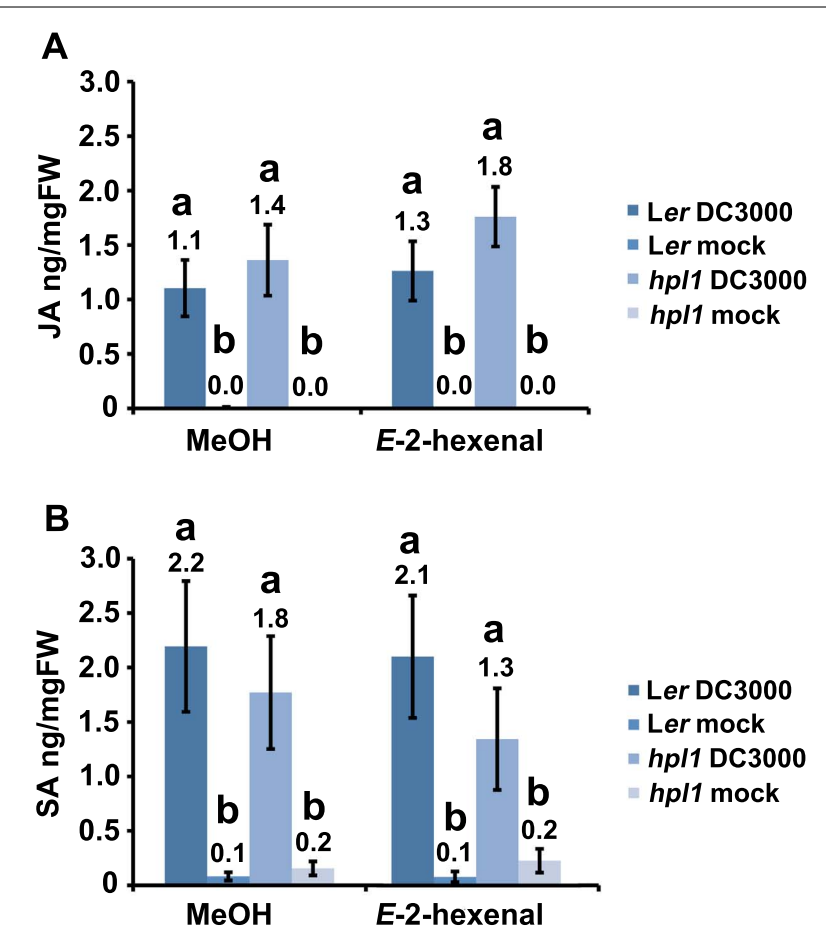

FIGURE A2 | E-2-hexenal does not induce changes in JA and SA levels in Ler and hpl1 plants infected with DC3000. (A) JA levels in Ler and $h p / 1$ plants pre-treated with $E$-2-hexenal or $\mathrm{MeOH}$ and subsequently infected with DC3000 (48 hpi); (B) SA levels in Ler and hp/1 plants pre-treated with $E$-2-hexenal or $\mathrm{MeOH}$ and subsequently infected with DC3000 (24 hpi). In both cases the hormone levels in the $10 \mathrm{mM} \mathrm{MgSO}_{4}$ (mock) infiltrated plants are also shown. Nine leaves were harvested, in pools of three from mock-infiltrated or bacteria-infiltrated plants at specified timepoints and used for plant hormone quantification. Bars represent the mean of three independent experiments. Error bars represent standard error. Bars annotated with different letters indicate statistically different hormone levels $(P<0.05$, according to ANOVA, followed by a LSD post hoc test). 